\title{
Biochemical Properties of Tracheobronchial Mucins from Cystic Fibrosis and Non-Cystic Fibrosis Individuals
}

\author{
MARY CALLAGHAN ROSE, CHARLES F. BROWN, JOHN Z. JACOBY, III,' W. S. LYNN, AND \\ BERNARD KAUFMAN
}

\begin{abstract}
Department of Child Health and Development, George Washington University; Children's Hospital National Medical Center, Washington, D.C. 20010 [M.C.R.] and Department of Biochemistry, Duke University Medical
\end{abstract} Center, Durham, North Carolina 27705 [C.F.B., W.S.L., B.K.]

\begin{abstract}
Tracheobronchial mucins from healthy individuals and from patients with bronchial asthma or cystic fibrosis (CF) were isolated from lung mucus, purified, and their chemical and physical properties compared. Normal and asthmatic mucins required both a dissociating and a reducing agent for solubilization and exhibited identical chromatographic behavior on Sepharose 4B, Sepharose $2 B$, and hydroxylapatite and similar amino acid and carbohydrate compositions. In contrast, 1) CF lung mucins were solubilized in the absence of dissociating and/or reducing agents and 2) the majority of the $C F$ mucins analyzed was eluted in the included volume of Sepharose $4 \mathrm{~B}$ with $K_{d}$ values of $0.3 \pm 0.1$ rather than in the void volume and thus appeared smaller than normal and asthmatic mucins. The lower molecular weight mucins in CF sputum apparently are produced by bacterial or inflammatory cell proteinases since radiolabelled asthmatic mucin was digested to smaller fragments when incubated with crude $C F$ lung mucosal samples. Furthermore, mucins secreted by tracheal explants from $C F$ and from non-CF individuals eluted in the void volume on Sepharose $4 B$, suggesting that CF tracheobronchial mucins were not inherently smaller than non-CF mucins. (Pediatr Res 22: 545-551, 1987)
\end{abstract}

\section{Abbreviations}

BGA, blood group activity

BA, bronchial asthma

CF, cystic fibrosis

DTT, dithiothreitol

ME, 2-mercaptoethanol

$\mathbf{N}$, normal

SDS, sodium dodecyl sulfate

TBM, tracheobronchial mucin

$V_{\text {o }}$, void volume

MEM, minimal essential medium

PMSF, phenylmethylsulfonyl fluoride

$\mathrm{CF}$ is the most prevalent recessive genetic disease of Caucasians (1). A major pathological manifestation of $\mathrm{CF}$ is the blockage by

\footnotetext{
Received November 24, 1968; accepted June 26, 1987. Correspondence and reprint requests M. C. Rose, Ph.D., Department of Pulmonary Medicine, Children`s reprint requests M. C. Rose, Ph.D., Department of Pulmonary Medicit National Medical Center, 111 Michigan Avenue, N.W., Washington, D.C. 20010.

Supported by Grants HL24896 and HL33152 from the National Heart, Blood, and Lung Institute.

1 Present address Cystic Fibrosis Center, Department of Pediatrics, St. Vincent's Hospital, 36 Seventh Avenue, New York, NY 10011
}

mucus of exocrine glands or epithelial tubular systems of the respiratory, gastrointestinal, and reproductive tracts (2) which is the basis for the generally held assumption that CF mucus is "abnormal." Since mucus glycoproteins (mucins) are the macromolecules responsible for the viscoelastic properties of mucus (3-5), alterations in mucin structure could effect the physiological behavior of mucus.

To date, the most comprehensive studies on CF mucins (6-8) have utilized TBM isolated from CF sputum as copious amounts of such material are readily available. There is limited information available on TBM from healthy airways primarily because of the difficulties in obtaining sufficient amounts of adequate material for analysis. Thus, insufficient information currently exists to determine whether CF and non-CF mucins are different (see Ref. 9 for review) although available studies suggest differences in sulfation of CF respiratory tract mucins (10). However, recent studies have suggested that TBM from healthy airways exhibit physical properties (size, chromatographic behavior on molecular sieving, solubility) different than those of mucins from pathological airways (11-13). While isolating and purifying human mucins from normal and pathological mucus, we obtained results that indicated that CF TBM were considerably more heterogeneous and smaller in size than non-CF TBM. The smaller size of CF mucins in the samples analyzed could result from in vivo proteolysis, as CF airways are chronically infected with pathogens that produce proteinases $(14,15)$ and both $C F$ sputum and bronchial washings contain high levels of extracellular proteinase activity (16-18). Alternatively, the smaller mucins could reflect inherent differences in $\mathrm{CF}$ mucins. These possibilities were examined; the former interpretation was supported by studies reported herein.

\section{MATERIALS AND METHODS}

Materials. All chemicals were obtained from commercial sources and were of the highest available purity. Mucosal samples were obtained from the airways of adult volunteers ( $\mathrm{N}-1,21-\mathrm{yr}-$ old man; N-2, 34-yr-old woman) via the hypertonic saline stimulation procedure of Barton et al. (11), whereas BA and CF samples (BA, 29-yr-old woman; CF-1, 21-yr-old woman; CF-2, 22-yr-old man; CF-3, 18-yr-old man) were obtained on expectoration. All samples were collected on ice and were frozen at $-20^{\circ} \mathrm{C}$. Tracheas for explant cultures were obtained within 3 to $6 \mathrm{~h}$ after death of a 16-year-old girl with CF and from a 69-yrold man with no chronic obstructive pulmonary disease.

Isolation and purification of mucins. The procedures used for the solubilization and chromatographic resolution of the components of LM-gel and for the purification of tracheobronchial mucins have been described (5). Briefly, the samples were thawed, diluted with saline, homogenized, heated in a boiling 
water bath for $10 \mathrm{~min}$., dialyzed overnight versus water, separated by centrifugation into soluble and insoluble phases, lyophilized, and weighed. Samples were either 1) reduced and carboxymethylated and dialyzed as previously described (5) and chromatographed on Sepharose 4B with buffer A $(0.15 \mathrm{M}$ ammonium acetate, $\mathrm{pH} 7.0,0.1 \% \mathrm{SDS}$ ) or 2) solubilized in buffer A that had been made $1 \%$ in SDS and $0.02 \mathrm{M} \mathrm{ME}$ and chromatographed on Sepharose gels with eluent buffer $A$ which had been made $0.02 \mathrm{M}$ in $\mathrm{ME}$. The mucin fractions were purified as described in the text.

Radiolabeling of TBM. Radiolabeled mucin was prepared by reductive carboxyamidomethylation with iodo $\left[1-{ }^{14} \mathrm{C}\right]$ acetamide. Five mg of BA mucin that had been purified by procedure B was solubilized in $1 \mathrm{ml}$ of reducing buffer ( $1 \%$ SDS, $0.1 \mathrm{M}$ tris, $0.2 \%$ EDTA, 0.01 M DTT, pH 8.5) at room temperature for $4 \mathrm{~h}$. Thirty $\mu$ mol of sodium arsenite was added to the sample to destroy excess DTT. After $5 \mathrm{~min}, 100 \mu \mathrm{l}$ containing $5 \mu \mathrm{mol}$ of iodoacetamide, and $5 \mu$ mol iodo $\left[1-{ }^{14} \mathrm{C}\right]$ acetamide $(19.1 \mu \mathrm{Ci} /$ $\mu \mathrm{mol}$; New England Nuclear) was added; alkylation was carried out in the dark for $1 \mathrm{~h}$. The $\mathrm{pH}$ was adjusted to 4.5 ; the sample was dialyzed extensively (5) and lyophilized.

Analytical procedures. Assays were performed as previously described (5) except as noted below. Amino acid analyses were performed with a Glenco custom modular analyzer using a dual temperature, single column system with a $9 \mu \mathrm{m}, 12 \%$ crosslinked resin (Glenco CX-9-12). The components of the mixtures were resolved with Pierce Picobuffer system II, sodium citrate form. Duplicate samples for amino acid analyses were hydrolyzed at a concentration of $50-500 \mu \mathrm{g} / \mathrm{ml}$ in $6 \mathrm{~N} \mathrm{HCl}$ for $20 \mathrm{~h}$ under vacuum at $100^{\circ} \mathrm{C}$ (optimal conditions selected from hydrolysis curves of BA mucin). Samples for hexosamine analyses were hydrolyzed for $6 \mathrm{~h}$ at $100^{\circ} \mathrm{C}$ and resolved at $56^{\circ} \mathrm{C}$ on the Glenco analyzer by elution with sodium citrate-borate buffer (19). Monosaccharides were analyzed by gas liquid chromatography of the trimethylsilyl derivatives of the methyl glycosides using a slight modification of the procedure of Bhatti et al. (20). Sialic acid was determined by the thiobarbituric acid method of Aminoff (21). Sulfate was determined by the barium chloranilate procedure of Spencer (22) after hydrolysis for $6 \mathrm{~h}$ in $1 \mathrm{~N} \mathrm{HCl}$ at $100^{\circ}$ $\mathrm{C}$ and by the rhodizonate method of Silvestri et al. (23) after alkaline hydrolysis. Both procedures yielded values that agreed within $5 \%$; the rhodizonate procedure was more sensitive, faster, easier to perform, and required considerably less material. Sulfate values were corrected, where necessary, for trace amounts of SDS as determined by the methylene blue reaction of Takagi et al. (24). Blood group titers were measured with 2 hemaglutinating units of anti-A or anti-B serum or Ulex Europas agglutinin-1 (Miles-Yeda Ltd.) and a $2 \%$ suspension of A, B, or O red blood cells (25). Electrophoresis was carried out on $5 \%$ polyacrylamide or $3 \%$ polyacrylamide $/ 0.5 \%$ agarose gels according to the procedure of Holden et al. (26) and stained with Coomassie blue or periodic acid-Schiff reagents. The mucin samples were incubated overnight in electrophoresis sample buffer that contained ME before loading.

Enzymatic assays. Proteinase activity was assayed by a colorimetric procedure. The reaction mixture contained $100 \mu \mathrm{l}$ of homogenized sample and $100 \mu \mathrm{l}$ of casein yellow $(0.3 \mathrm{mg})$ suspended in $0.01 \mathrm{M} \mathrm{NaCl}$. After incubation at $37^{\circ} \mathrm{C}$ for $0-3 \mathrm{~h}$, the reaction was stopped by adding $0.5 \mathrm{ml}$ of ice cold $5 \%$ phosphotungstic acid. The insoluble protein was sedimented by centrifugation at $3000 \times g$ for 5 min. The supernatant was removed, made alkaline by adding $150 \mu \mathrm{l}$ of $4 \mathrm{M} \mathrm{NaOH}$, and the absorbance measured at $428 \mathrm{~nm}$. Hyaluronidase assays were carried out with bovine testicular hyaluronidase $(300 \mathrm{U} / \mathrm{ml})$ (Calbiochem) which had no detectable proteinase activity when tested with albumin and which was active when tested with hyaluronic acid and monitored by orcinol assay. To $0.5 \mathrm{ml}$ of

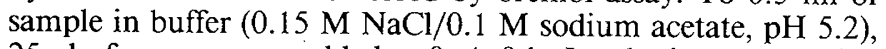
$25 \mu \mathrm{l}$ of enzyme was added at $0,4,8 \mathrm{~h}$. Incubation was carried out for $24 \mathrm{~h}$ at $37^{\circ} \mathrm{C}$. The enzyme was inactivated by increasing the $\mathrm{pH}$ to 7.0. Chromatography was carried out on Sepharose $4 \mathrm{~B}$ with $0.15 \mathrm{M}$ ammonium acetate, $\mathrm{pH} 7.0$, as eluent buffer.

Tracheal explant cultures and isolation of radiolabeled mucin in vitro. Tracheas were rinsed several times in ice-cold transport media which contained $100 \mu \mathrm{g}$ of tobramycin sulfate and $1.1 \mu \mathrm{g}$ of amphotericin per $\mathrm{ml}$ of media. The submucosa-mucosa layers were microdissected from the underlying cartilage and serosa. The tissues were cultured as $2-4 \mathrm{~mm}^{2}$ explants in $35-\mathrm{mm}$ Petri dishes as described by Boat and coworkers $(27,28)$ except for the following modifications. MEM (Eagle's base) supplemented with nonessential amino acids (at the concentrations in Media 199) was used and the sulfate concentration was reduced to $0.1 \%$ of that normally used in MEM. The media contained tobramycin base (gift of Lilly Research Laboratories), $50 \mu \mathrm{g} / \mathrm{ml}$; amphotericin $\mathrm{B}, 0.25 \mu \mathrm{g} / \mathrm{ml}$; and carbenicillin $250 \mu \mathrm{g} / \mathrm{ml}$. Explants were cultured in a $5 \% \mathrm{CO}_{2} / 95 \%$ air water-saturated environment at $37^{\circ}$ C.

Radiolabels were added to the culture media at the time of incubation. Every $24 \mathrm{~h}$ the culture media were removed, the tissue was washed with unlabeled media, and fresh media and radiolabel were added. The culture media and washes were combined and centrifuged briefly. Two volumes of a proteinase inhibitor solution $(0.01 \mathrm{M}$ EDTA, $0.1 \mathrm{M} \epsilon$-amino caproic acid, $5 \mathrm{mM}$ benzamidine $\mathrm{HCl}, 1 \mathrm{mM}$ phenylmethylsulfonyl fluoride, $10 \mathrm{mM}$ N-ethylmaleimide) were added and the media was dialyzed versus $100 \mathrm{ml}$ of the proteinase inhibitor solution in the cold overnight and then versus 21 of water for $24 \mathrm{~h}$ with two changes of water and lyophilized.

Labeled mucins were isolated from other labeled macromolecules by chromatography on Sepharose 4B-CL. The void volume fractions were dialyzed versus urea/ $\mathrm{NaCl}$ and then water to remove SDS (5) and then lyophilized. The samples were dissolved in a $10 \mathrm{mM}$ sodium phosphate $\mathrm{pH} 6.5 / 4 \mathrm{M} \mathrm{GuHCl}$ buffer containing proteinase inhibitors $(5 \mathrm{mM}$ NaEDTA; $5 \mathrm{mM} \mathrm{N}$ ethylmaleimide; $1 \mathrm{mM}$ PMSF; $2.5 \mathrm{mM}$ benzamidine $\mathrm{HCl} ; 0.05$ $\mathrm{M} \epsilon$-aminocaproic acid). The density was adjusted to $1.42 \mathrm{~g} / \mathrm{ml}$ with cesium chloride. Isopycnic density centrifugation was carried out at $15^{\circ} \mathrm{C}$ for $72-80 \mathrm{~h}$ at 32,000 rpm in a Beckman L565 ultracentrifuge $(8 \times 12 \mathrm{ml}$ rotor $)$. Fractions were collected from the bottom of the tubes and $100-\mu 1$ aliquots were weighed for density calculations. Aliquots of the eluates were counted in Aquasol-2 on a Packard Scintillation Counter.

\section{RESULTS}

Extraction of TBM. Lung mucosal samples were separated by centrifugation into soluble and insoluble/gel phases and analyzed for protein, hexose, and units of BGA. The latter is a more reliable estimate of mucin than neutral hexose as neutral hexose is present in both mucins and in serum-type glycoproteins, whereas serum-type glycoproteins do not contain blood group determinants (29). Blood group activity was specific to mucin in these samples; no glycolipids with BGA were detected in lung mucosal samples. In two (N-1 and BA-1-xv) of the five samples reported in Table 1 the distributions of protein and hexose between the soluble and the gel phases and the specific activities of the blood group hapten (measured either as $\mathrm{BGA} / \mathrm{mg}$ hexose or BGA/mg of lyophilized powder) were in close agreement with values previously reported for several mucosal samples from a BA patient (5), i.e. about two-thirds of the total TBM remained in the gel phase. In contrast, the three CF lung mucosal samples differed markedly from both normal and asthmatic samples: 1) the insoluble phases of the CF samples were precipitates rather than gels; and 2) the ratio of BGA units in the two phases indicated that the $\mathrm{CF}$ insoluble phases contained only traces of mucin; essentially all of the TBM in the CF samples was in the soluble phase.

The distribution of mucin between the two phases of a single sample could be estimated by measuring BGA units; however, this procedure could not be used for comparing the mucin 
content of different samples since the number of completed carbohydrate chains (chains carrying the blood group determinants) vary (32). Thus, the mucin content of the dialyzed, lyophilized mucosal samples was determined on a weight basis after chromatographic resolution of the mucins on Sepharose $4 \mathrm{~B}$ (Figs. 1 and 2). The mucin content was $40-50 \%$ for normal (fraction I; Fig. 1 $A$ ), 20-30\% for asthmatic (fraction 1; Fig. 1B), and $12-14 \%$ for CF mucosal samples (fractions Ib and II; Fig. 2).

Isolation of TBM by molecular sieving. Typical chromatographic profiles obtained with the gel phase of normal and of asthmatic samples are shown in Figure 1 . The $V_{0}$ fractions

Table 1. Analyses of soluble and insoluble fractions of human lung mucus

\begin{tabular}{lcccc}
\hline \multicolumn{1}{c}{ Sample } & $\begin{array}{c}\mathrm{Wt}^{*} \\
(\mathrm{mg})\end{array}$ & $\begin{array}{c}\text { Protein } \dagger \\
(\mathrm{mg})\end{array}$ & $\begin{array}{c}\text { Hexose } \\
(\mathrm{mg})\end{array}$ & $\mathrm{BGA} \times 10^{-5} \S$ \\
\hline Normal & & & & \\
$\quad \mathrm{N}-1$ sol & 46 & 9.1 & 6.6 & $4.7(\mathrm{~A})$ \\
$\quad$ insol & 54 & 6.5 & 8.9 & 11 \\
Bronchial asthma & & & & \\
$\quad$ BA-1-xv sol & 33 & 5.4 & 3.9 & $1.7(\mathrm{AB})$ \\
insol & 67 & 17 & 6.6 & 3.4 \\
CF & & & & \\
CF-1 sol & 53 & 17 & 3.8 & $22(\mathrm{~A})$ \\
insol & 47 & 11 & 1.7 & 0.08 \\
CF-2 sol & 64 & 20 & 8.1 & $13(\mathrm{~B})$ \\
insol & 36 & 15 & 2.4 & 0.06 \\
CF-3 sol & 55 & 16 & 5.3 & $0(\mathrm{NS})$ \\
insol & 45 & 15 & 2.3 & 0 \\
\hline
\end{tabular}

* Results are expressed per $100 \mathrm{mg}$ of dialyzed, lyophilized lung mucus. † Assayed by procedure of Lowry et al. (30).

$\$$ Neutral hexose, assayed by procedure of Dubois et al. (31).

$\S$ Units and types of BGA: A, B, AB, NS (nonsecretor). Assayed by hemagluttination assay of Kabat (32).

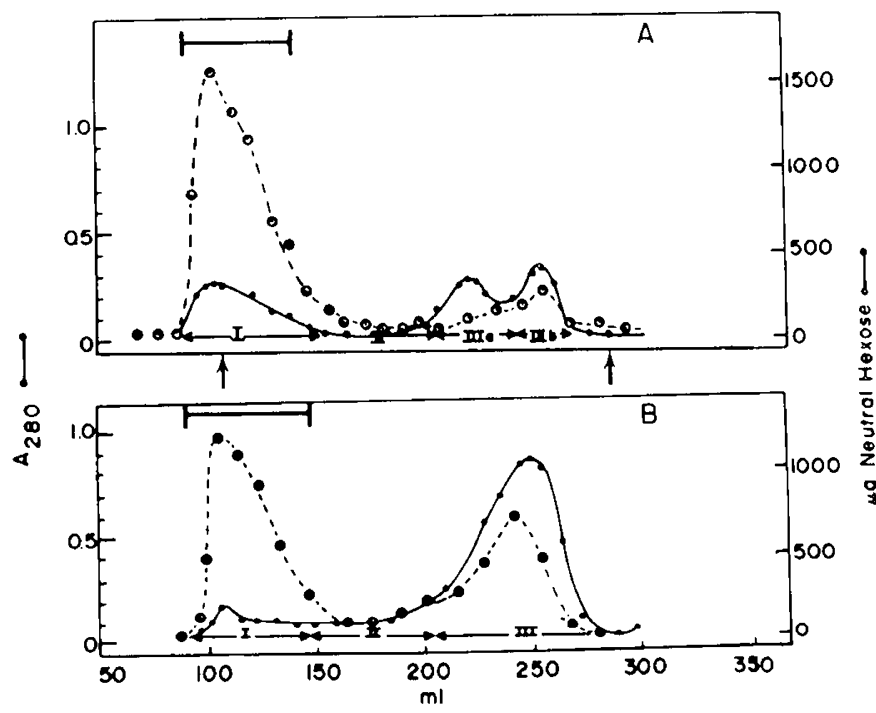

Fig. 1. Chromatography of reduced carboxymethylated normal and asthmatic tracheobronchial mucus on Sepharose $4 B(90 \times 2 \mathrm{~cm})$. The carboxymethylated gel phase material was dissolved in $7.5 \mathrm{ml}$ of a solution of $1 \%$ SDS, $0.15 \mathrm{M}$ ammonium acetate. The solution was layered onto a Sepharose $4 \mathrm{~B}$ bed and the components were eluted with eluent buffer $(0.1 \%$ SDS, $0.15 \mathrm{M}$ ammonium acetate, $\mathrm{pH} 7.0)$. The eluate was monitored for protein by $\mathrm{A}_{280}(-\infty)$ and for neutral hexose $(\mathrm{O}-\mathrm{O})$ by the phenol sulfuric acid assay (31). The fractions were pooled as indicated, dialyzed to remove the buffer, and assayed for blood group activity (- $)$. The $\mathrm{V}_{\mathrm{o}}$ and salt peak are indicated by arrows. $A$, $80 \mathrm{mg}$ of $\mathrm{N}-1 ; B, 114 \mathrm{mg}$ of $\mathrm{BA}-1-\mathrm{xv}$.

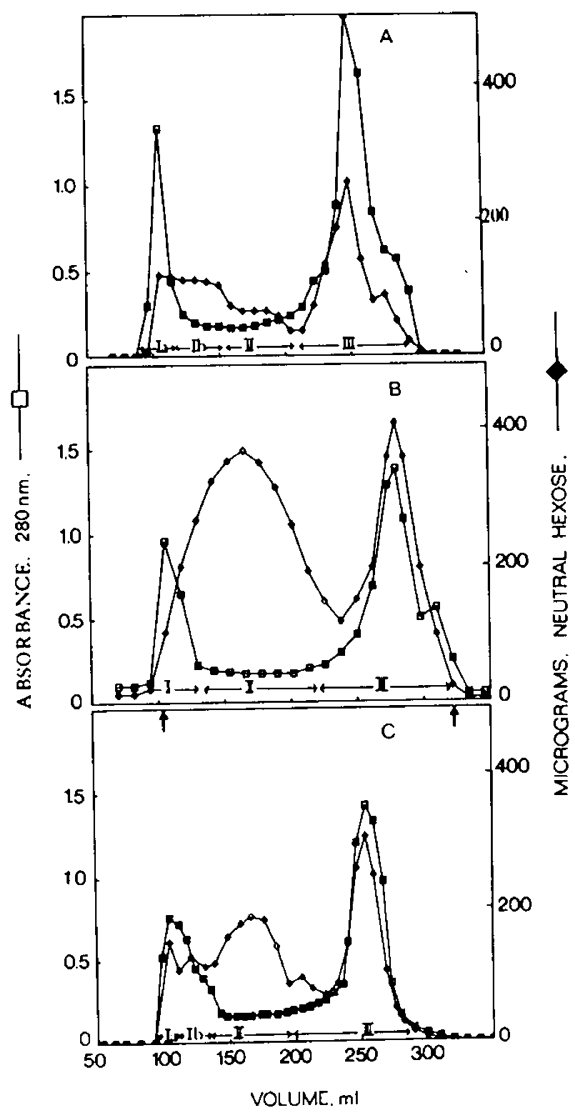

Fig. 2. Chromatography of reduced carboxymethylated CF lung mucosal samples on Sepharose $4 B(93 \times 2 \mathrm{~cm})$. Chromatography was carried out with $100-\mathrm{mg}$ samples as described in the legend to Figure 1. Absorbance, $280 \mathrm{~nm}(-\square)$; ug of neutral hexose (--). A, CF-1, B, CF-2; $C$, CF-3.

contained the mucus glycoprotein components: they were high in neutral hexose, low in protein, and contained all of the BGA activity in the starting sample. The $\mathrm{V}_{\mathrm{o}}$ fractions $(90-150 \mathrm{ml}$, Fig. 1) eluted as a broad, skewed peak. When the tail (120-150 ml, Fig. $1 A$ ) of the peak was rechromatographed on Sepharose 4B, its hexose and $A_{280}$ profiles were similar to that of the $V_{0}$ peak observed for fraction I (Fig. $1 A$ ). Mucin isolated by method $\mathrm{B}$ as described in "Materials and methods" exhibited profiles on Sepharose 4B identical to those of reduced carboxymethylated samples shown in Figure $1 A$ and $B$. The profiles of the soluble phases of the samples (not shown) were similar to those of the gel phases in that most of the hexose and all of the BGA in the samples eluted in the $V_{o}$ fraction. However the concentration $(w / w)$ of fraction I decreased and that of fraction III increased by 20 to $30 \%$.

In contrast to the normal and asthmatic samples, CF mucins were isolated from the soluble rather than the insoluble phases of the CF samples as the soluble phases were elevated in BGA and hexose (Table 1) and the insoluble pellets of the CF samples contained essentially no mucin. The chromatographic profiles of three CF mucosal samples on Sepharose 4B (Fig. 2) clearly differed from those of normal and asthmatic samples (Fig. 1) and from one another. Hexose was present in all fractions; the sharp $A_{280}$ peaks in the $V_{o}$ of samples CF-1 and CF-2 did not cochromatograph with hexose and disappeared on treatment with DNAase. Since $80 \%$ of the BGA in the sample was recovered in fraction Ib of CF-1 (Fig. $2 A$ ) and $95 \%$ in fraction II of CF-2 (Fig. $2 B$ ), fractions Ib and II of CF-3 (Fig. 2C) were considered to be mucin-rich.

Purification of human tracheobronchial mucins. The mucinrich fractions of normal and asthmatic mucus (the $V_{0}$ fractions 


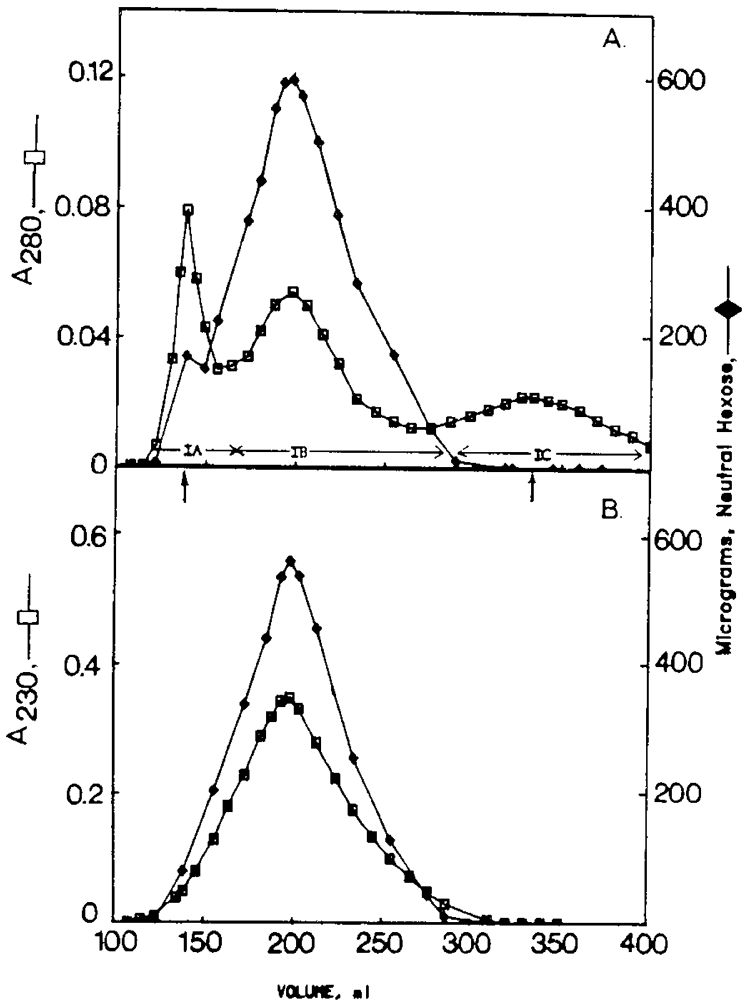

Fig. 3. $A$, chromatography of carboxymethylated normal (N-1) lung mucin on Sepharose 2B. Fraction I (A) was pooled, dialyzed, lyophilized, and dissolved in $10 \mathrm{ml}$ of eluent buffer $(0.1 \%$ SDS and $0.15 \mathrm{M}$ ammonium acetate, $\mathrm{pH}$ 7.0). The solution was layered onto a Sepharose $2 \mathrm{~B}$ bed $(108 \times 2 \mathrm{~cm})$ and the components eluted with eluent buffer. The fractions $(4.7 \mathrm{ml})$ were monitored for protein by $A_{280}(-\square-)$ and for neutral hexose (31) (- -). The $\mathrm{V}_{\mathrm{o}}$ and salt peaks are indicated by arrows. B, rechromatography of fraction IB on Sepharose 2B. The IB fraction from $A$ was pooled, lyophilized, taken up in $7 \mathrm{ml}$ of water, dialyzed versus the eluent buffer, and chromatographed as described above, except that the absorbance was monitored at $230 \mathrm{~nm}(-\square-)$.

of Sepharose 4B, Fig. 1) were further purified by chromatography on Sepharose 2B and hydroxylapatite. Most of the hexose eluted with a $\mathrm{K}_{\mathrm{d}}$ of 0.3 (fraction Ib, Fig. $3 \mathrm{~A}$ ) on Sepharose 2B. Rechromatography of IB yielded a single, somewhat broad, included peak; no $V_{\circ}$ or smaller included components were observed (Fig. $3 B$ ).

The purity of the IB mucin fraction (Fig. $3 B$ ) was investigated by electrophoresis. The material was free of smaller protein or glycoprotein components; no bands that stained with Coomassie blue or Schiffs reagent were observed to enter $3 \%$ polyacrylamide $/ 0.5 \%$ agarose gels even when $500 \mu \mathrm{g}$ of mucin was loaded in a sample buffer that contained $2 \%$ ME. The rechromatographed mucin fraction (Fig. $3 B$ ) was further purified by chromatography on hydroxylapatite; hexose and $A_{280}$ coeluted as sharp peaks with $0.3 \mathrm{M}$ phosphate buffer; a minor component ( $10 \%$ by weight of the applied sample) eluted with $0.5 \mathrm{M}$ phosphate (data not shown).

The LM-gel sample from N-2 (a nonsecretor) was processed without centrifugation into two phases; otherwise TBM was isolated by method B as described in "Materials and methods." Its profiles on Sepharose $4 \mathrm{~B}$ and $2 \mathrm{~B}$ were almost identical to those shown for $\mathrm{N}-1$ (Fig. $1 A$ ). Increasing the mercaptoethanol concentration 10 -fold (to $0.2 \mathrm{M}$ in both the sample and eluent buffer) did not alter the $\mathrm{K}_{d}$ of TBM (fraction IB) on Sepharose 2B nor did it release detectable lower molecular weight protein fractions.

The CF lung mucins in fractions Ib and II (Fig. 2) were also purified by chromatography on Sepharose 2B and on hydroxyl- apatite. They eluted as a broad peak on Sepharose $2 \mathrm{~B}$ with a $\mathrm{K}_{\mathrm{d}}$ $\sim 0.5$, and often appeared to elute as two or more closely overlapping fractions. The mucin samples did not enter 3-5\% polyacrylamide gels; no smaller protein or glycoprotein components were observed. Chromatography of the CF mucins on hydroxylapatite yielded fractions that eluted with $0.15,0.3$, and $0.5 \mathrm{M}$ phosphate buffer. Fifty percent of the mucin in the three $\mathrm{CF}$ samples examined was eluted with $0.3 \mathrm{M}$ phosphate and varying amounts were eluted with 0.15 and $0.5 \mathrm{M}$ phosphate buffer.

Characterization of TBM. Analyses of all mucin samples were carried out; only the compositions of purified mucins isolated from blood group A secretors (N-1, BA-1, CF-1) are reported (Table 2). All mucins exhibited a similar spectrum of amino acids: threonine, serine, and proline accounted for $40-51 \%$ of the amino acid residues; only low concentrations of hydrophobic and basic amino acids were detected.

The mucins contained $\mathrm{N}$-acetylgalactosamine, $\mathrm{N}$-acetylglucosamine, galactose, fucose, and N-acetylneuraminic acid. Neither mannose nor glucose were detected, with the limit of detection being $1 \%$ of the galactose content. Sulfate was variable and present at moderate concentrations $(210-780 \mathrm{nmol} / \mathrm{mg})$; these values were within the ranges previously reported for mucins isolated from nonpathological, bronchitic, and CF airways (33).

TBM that had been isolated by method B from healthy $(\mathrm{N}-2)$ or asthmatic airways was capable of forming viscoelastic gels and exhibited measurable viscous and elastic moduli at mucin concentrations $\geq 12.5 \mathrm{mg} / \mathrm{ml}$ after removal of dissociating and reducing agents (34). TBM from CF airways was not viscoelastic even at concentrations of $50 \mathrm{mg} / \mathrm{ml}$. The CF mucosal samples analyzed did, however, exhibit viscoelastic behavior before fractionation (34) presumably because of the high concentrations of DNA found in such samples (35).

Proteinase activity in lung mucus. Proteinase activity was not detected in the asthmatic and normal samples used in this study. Appreciable proteinase activity was detected in the three CF

Table 2. Compositional analyses of human $T B M^{*}$

\begin{tabular}{|c|c|c|c|}
\hline \multirow[b]{2}{*}{ Amino acid } & $\mathrm{N}-1$ & BA-1-xv & $\mathrm{CF}-1$ \\
\hline & \multicolumn{3}{|c|}{ Residues 1000 residues } \\
\hline Asp & 50.0 & 43.8 & 42.8 \\
\hline Thr & 196 & 222 & 200 \\
\hline Ser & 129 & 163 & 178 \\
\hline Glu & 74.6 & 68.2 & 90.0 \\
\hline Pro & 79.4 & 129 & 85.7 \\
\hline Gly & 78.4 & 64.0 & 109 \\
\hline Ala & 94.1 & 68.2 & 86.2 \\
\hline Cys $\dagger$ & 21.5 & 29.8 & 8.29 \\
\hline Val & 49.7 & 37.7 & 36.2 \\
\hline Ileu & 20.6 & 22.4 & 16.8 \\
\hline Leu & 56.0 & 33.5 & 39.8 \\
\hline Tyr & 21.7 & 16.4 & 23.6 \\
\hline Phe & 28.8 & 17.4 & 19.7 \\
\hline Lys & 25.5 & 25.7 & 23.2 \\
\hline His & 27.8 & 26.4 & 23.4 \\
\hline Arg & 41.1 & 32.8 & 17.9 \\
\hline Carbohydrate & \multicolumn{3}{|c|}{$\mathrm{nmol} / \mathrm{mg}$} \\
\hline $\mathrm{GlcNH}_{2}$ & 535 & 312 & 428 \\
\hline $\mathrm{GalNH}_{2}$ & 443 & 443 & 465 \\
\hline Galactose & 884 & 653 & 874 \\
\hline Fucose & 715 & 519 & 751 \\
\hline NeuAc & 63.2 & 280 & 92.5 \\
\hline Sulfate & 550 & 295 & 250 \\
\hline BGA & A & $\mathrm{AB}$ & A \\
\hline
\end{tabular}

* TBM fraction eluted from hydroxylapatite column with $0.3 \mathrm{M}$ phosphate buffer.

$\dagger$ Determined as S-carboxymethylcysteine. 
mucosal samples examined and it decreased to baseline values on heating. Proteinase levels were generally four times higher in the CF-2 sample than in the CF-1 and CF-3 samples. However, samples collected at different times from the same CF individuals exhibited varying levels of proteinase activity.

In order to determine whether the proteinases detected in $\mathrm{CF}$ lung mucosal samples were capable of digesting larger tracheobronchial mucins, purified BA mucin (whose thiol groups had been radiolabeled by carboxyamidomethylation with iodo [1${ }^{14} \mathrm{C}$ ] acetamide) was incubated at $37^{\circ} \mathrm{C}$ for $16 \mathrm{~h}$ in freshly thawed sputum samples from CF-1 and CF-2 individuals. After incubation the samples were processed as usual, solubilized in a buffer containing SDS and ME, and chromatographed on Sepharose 4B. No fragmentation of the radiolabeled mucin incubated in saline was observed; it eluted in the $\mathrm{V}_{0}$ on Sepharose 4B (Fig. $4 A$ ). Approximately $87 \%$ of the radioactivity of the BA mucin incubated in the CF lung mucosal samples was lost during dialysis, suggesting that most of the BA mucin was fragmented during the 16-h incubation. The nondialyzable radioactive material contained several fragments (Fig. $4 B$ and $C$ ); the major nondialyzable radioactive fraction generated by both $C F$ samples eluted with a $K_{d}$ of 0.37 on Sepharose $4 B$, a value similar to that of CF mucins (Fig. 2).

Biosynthetically labeled $C F$ and non-CF TBM. Tracheal explants from $C F$ and non-CF tissue were radiolabeled with $\left[{ }^{35} \mathrm{~S}\right]$ sulfate which is a marker for human $\operatorname{TBM}(10,36)$. The secretions from both $\mathrm{CF}$ and non-CF tracheal explants yielded two radiolabeled fractions when analyzed by chromatography on Sepharose $4 B$ (Fig. 5). The $V_{o}$ fractions, the presumptive mucincontaining fraction, eluted as single peaks on analytical density centrifugation in $\mathrm{CsCl} / 4 \mathrm{M} \mathrm{Gu} \mathrm{HCl}$ (data not shown) with

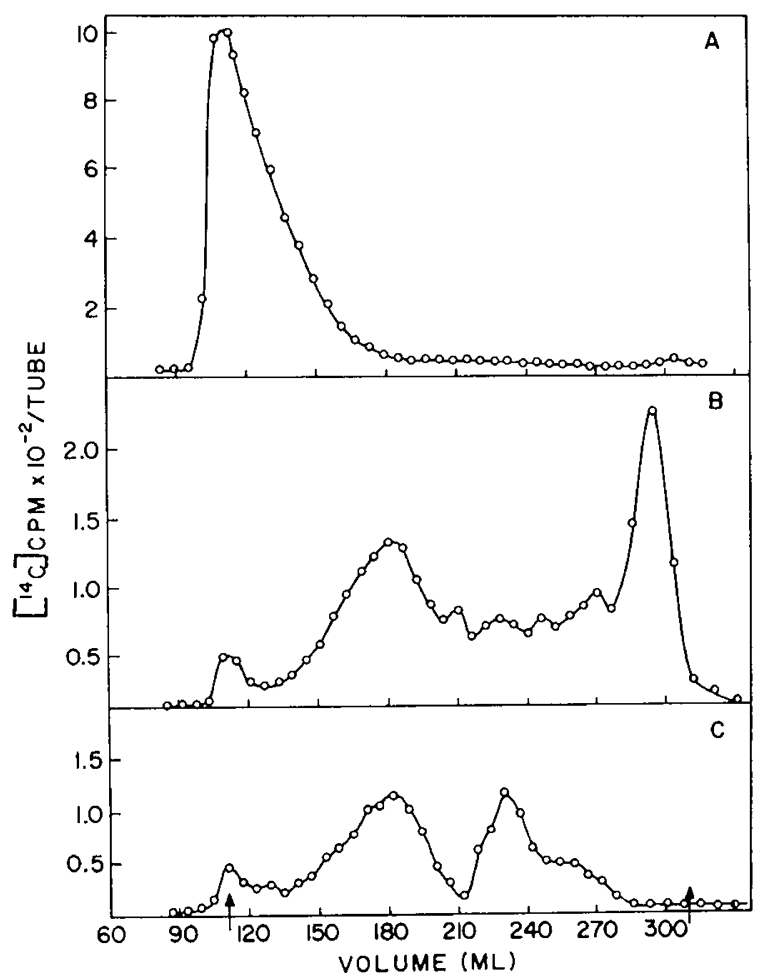

Fig. 4. Chromatography on Sepharose $4 \mathrm{~B}$ of ${ }^{14} \mathrm{C}$-mucin. Radiolabeled BA mucin $\left(7.5 \times 10^{5} \mathrm{cpm}\right)$ was incubated in $2 \mathrm{ml}$ of CF mucosal gel samples or saline at $37^{\circ} \mathrm{C}$ for $16 \mathrm{~h}$. The mixture was then processed (homogenized in $3 \mathrm{vol}$ of isotonic saline, heated in a boiling water bath for $10 \mathrm{~min}$, dialyzed, and lyophilized), solubilized in eluent buffer and chromatographed on Sepharose 4B. Total cpm per tube is plotted on the ordinate. $A,{ }^{14} \mathrm{C}$-mucin incubated in saline; $B,{ }^{14} \mathrm{C}$-mucin incubated in a CF-1 mucosal sample; $C,{ }^{14} \mathrm{C}$-mucin $\left(8.2 \times 10^{3} \mathrm{cpm}\right)$ incubated in a $\mathrm{CF}$ 2 mucosal sample. The $\mathrm{V}_{\mathrm{o}}$ and salt peaks are indicated by arrows.

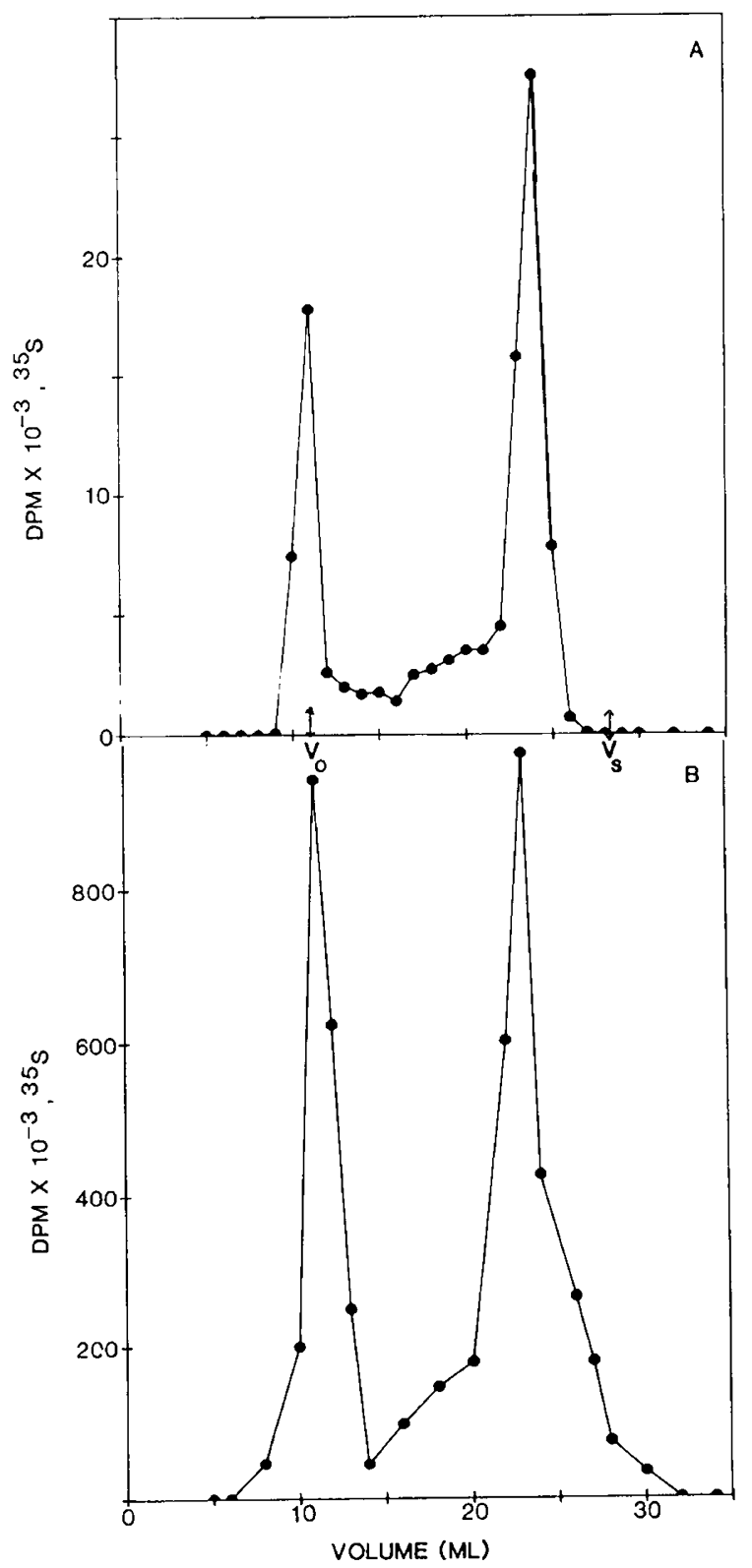

Fig. 5. Chromatography of radiolabeled macromolecules secreted by tracheal explants. Four and $100 \mu \mathrm{Ci}$ of carrier-free $\mathrm{H}_{2}{ }^{35} \mathrm{SO}_{4}$ (New England Nuclear) were added per $\mathrm{ml}$ of media, respectively, to the non-CF $(A)$ and $C F(B)$ explants every $24 \mathrm{~h}$. The secretions were collected as described in "Materials and methods." After dialysis and lyophilization, the radiolabeled secretions were solubilized in $0.5 \mathrm{ml}$ of column buffer $(0.1 \%$ SDS, 0.15 $\mathrm{M}$ ammonium acetate pH 7.0, 0.02 M ME) and chromatographed on Sepharose $4 \mathrm{~B}(30 \times 1 \mathrm{~cm})$. Appropriate aliquots were counted and dpm per tube plotted on the ordinate, $A$, non-CF tracheal explant; $B, C F$ tracheal explant.

buoyant densities characteristic of mucins $(1.42-1.45 \mathrm{~g} / \mathrm{ml})$. The purified radiolabeled mucins were further examined to determine whether the radiolabel had been incorporated into glycosaminoglycans by digesting the sample with bovine testicular hyaluronidase. Hyaluronidase will hydrolyze $\beta 1-4$ linkages between $\mathrm{N}$-acetylhexosamine and D-glucuronate residues in hyaluronic acid, chondroitin, and chondroitin 4- and 6-sulfated glycosaminoglycans. When hyaluronidase-digested mucin samples were analyzed by gel chromatography on Sepharose 4B, the radiolabeled mucin eluted in the void volume and less than $5 \%$ of the radioactivity eluted in the salt peak, indicating the absence of secreted radiolabeled glycosaminoglycans that cofractionated 
with the biosynthetically labeled mucin fraction.

The radiolabeled secretions of several nasal polyp epithelial explants from CF and non-CF individuals have also been examined in detail as such material is easier to obtain than human tracheal explants and has characteristics of upper respiratory tract mucosa (10). In $10 \mathrm{CF}$ and non-CF nasal polyp secretions examined to date, a mucin-rich fraction has eluted in the $V_{o}$ on Sepharose 4B.

\section{DISCUSSION}

This study has demonstrated that TBM obtained from the airways of healthy individuals had similar solubility and chromatographic properties to TBM from a patient with bronchial asthma whereas TBM isolated from CF sputum had markedly different properties. In comparison to normal and asthmatic TBM, CF TBMs were 1) present in the soluble rather than the insoluble phase after centrifugation of lung mucus, 2) smaller, as determined by their elution positions on Sepharose 4B; and 3) did not form viscoelastic gels. The profiles that the CF lung mucins exhibited on Sepharose 4B (Fig. 2) suggested the presence in $C F$ lung mucus samples of a spectrum of glycoproteins of different sizes. While some CF TBM eluted in the void volume on Sepharose 4B, most of the mucin in the samples eluted with apparent $\mathrm{K}_{\mathrm{d}}$ values of $0.2-0.4$ which are within the range observed for TBM glycopeptide fragments obtained by proteolysis of mucins from patients with asthma, bronchitis and/or bronchorrhea (37-39).

Possible explanations for this variable chromatographic behavior were 1) CF TBM is synthesized as considerably smaller macromolecules than normal or asthmatic TBM, or 2) CF TBM isolated from sputum has already been digested in vivo by proteinases present in CF lung samples as a result of chronic bacterial infection and inflammation $(14,15)$. The former possibility appears unlikely as TBM synthesized in vitro by tracheal explants from both a non-CF and a $C F$ individual eluted in the $\mathrm{V}_{\mathrm{o}}$ on Sepharose 4B (Fig. $5 A$ and $B$ ) as does mucin secreted by nasal epithelial explants (data not shown). The latter possibility appears more likely as 1) proteinase activity was detected in the three CF LM-gel samples analyzed and was higher in samples enriched in mucin II (CF-2, Fig. $2 B$ ) relative to mucin Ib (CF-1, Fig. 2A). 2) CF lung mucus contained proteinases capable of digesting $88 \%$ of the purified radiolabeled BA lung mucin to dialyzable components in an $18 \mathrm{~h}$ incubation. 3) The $\mathrm{K}_{\mathrm{d}}$ of the major fraction of the radiolabeled nondialyzable mucin fractions produced by incubation in $\mathrm{CF}$ lung mucus samples (Fig. $4 B$ and $C$ ) were similar to $K_{d}$ values on Sepharose $4 B$ of TBM glycopeptide generated by proteolytic enzymes (37-39). 4) The cysteine contents of the CF lung mucins analyzed were considerably lower than those of normal and asthmatic mucins, and similar to values obtained on analysis of the proteolytically-digested glycopeptide fragments of asthmatic mucin $(39,40)$. However, considerable variability in the cysteine concentrations of tracheobronchial mucins has been reported $(5,6,33,38-43)$ and cysteine is often not measured quantitively as it requires almost a mg of purified mucin for accurate measurements in duplicate.

This present study has shown that fragmentation can occur in vitro when TBM is incubated with $\mathrm{CF}$ lung mucus samples, presumably because of the presence of extracellular proteinases in such material (16-18). Although CF sputum contains high levels of bacteria $(1,2,14)$ which are known to produce proteinases (15), recent studies (16-18) have indicated that the major proteinase activity in CF sputum is from host defense cells (neutrophils and alveolar macrophages) and that bacterial proteinases are likely to be effectively inhibited by the large amount of bacterial specific immunoglobulins (44). The consequences of proteinase activity in infected lungs is still under intense investigation by several laboratories. In addition to fragmenting TBM, bacterial and cellular proteinases may also increase mucin secretion in vivo in humans. Proteinases from Pseudomonas aerugi- nosa increase the secretory index of mucin secretion in rabbit tracheal explants (45). However, any resultant increase in mucin secretion may be offset by proteolysis of TBM as the mucin concentration (weight $\%$ of nondialyzable sputum) of CF samples is lower than that of normal and asthmatic samples. Since proteinases in the CF LM-gel samples fragmented radiolabeled tracheobronchial mucin in vitro (Fig. 4), proteinases in LM-gel samples from pathological airways may account for the variations in molecular weight, solubility, and chromatographic behavior reported for tracheobronchial mucins $(6,37-43,46)$.

This study has also demonstrated that TBM from healthy individuals exhibited physical and chemical properties similar to those of TBM from a patient with bronchial asthma (5). However, our results on TBM from healthy airways are at variance with results on normal TBM reported by some laboratories (1113). Although the normal TBM isolated in this study was obtained from healthy airways by the procedure of Barton et al. (11) our observations on the chromatographic behavior of TBM are somewhat different than theirs although results cannot eaily be compared as the procedures used for sample preparation and chromatography by each laboratory were quite different. Barton et al. (11) pooled mucosal samples from an unspecified number of volunteers and solubilized their sample by incubation at room temperature for $4 \mathrm{~h}$ in $0.2 \% \mathrm{ME}$ and then overnight at $4^{\circ} \mathrm{C}$. After dialysis and lyophilization, $6 \mathrm{M}$ urea and $0.2 \% \mathrm{ME}$ were required to dissolve the sample in loading buffer. However, these reagents were not included in the eluent buffer. (In our experience both dissociating and reducing agents must be included in both the loading and eluent buffers to prevent aggregation of the components of LM-gel.) Two hexose-rich components eluted on Sepharose 4B (11): a $V_{o}$ component and an included component that somewhat overlapped the tail of the $V_{o}$ fraction. While these fractions presumably contain TBM, they were not further purified and no compositional data were reported. In contrast to the study of Barton et al. (11), we were able to purify normal mucins without pooling samples; $10-15 \mathrm{mg}$ of mucin were isolated from LM-gel samples obtained from healthy individuals by hypertonic saline aerosol stimulation.

The TBM samples we have isolated from lung mucus of healthy airways appeared to be both smaller (13) and large (12) than TBM obtained by fiberoptic bronchoscopy. Williams et al. (13) reported that alcian-blue reactive peaks from human tracheobronchial mucus eluted in the $\mathrm{V}_{\mathrm{o}}$ and included volumes on Sepharose 2B when chromatography was carried out in the presence of urea and a reducing agent. While the $V_{\circ}$ peak was referred to as mucin, no characterization or analyses were reported to substantiate this claim. On the other hand, the mucin sample isolated from bronchial washings of healthy airways by Sachdev et al. (12) has a molecular weight of 69,400 daltons which is markedly smaller than the molecular weight values of 2 to $7 \times 10^{6}$ obtained with asthmatic, bronchitic and/or bronchorrhea TBM $(38,42,46)$ as well as with TBM isolated from tracheal aspirates of nonpulmonary patients $(33,43)$. The normal mucin isolated by Sachdev et al. (12) is also smaller than the tracheobronchial glycopeptide fragment $(\mathrm{MW}=150,000)$ obtained on pronase digestion of BA mucin (38). Unless normal tracheobronchial mucin isolated from lavage samples obtained by fiberoptic bronchoscopy is inherently smaller than mucin isolated from expectorated LM-gel samples and from tracheal aspirates, some step in the processing procedure of the lavage fluid likely results in fragmentation of the mucin. It has recently been shown by electron microscopy and molecular sieving studies that sonication of human TBM yields smaller molecules (47). Presumably, the mucin molecules in the lavaged samples (11) could be fragmented either by sonication (which procedure was used by Sachdev et al. (11) to dissolve the lyophilized sample prior to chromatography) or by proteinases released by freezing and thawing of lung cells present in lavaged secretions (48).

In summary, this study demonstrates that TBM isolated from $\mathrm{CF}$ lung mucus is not an ideal material for investigating or 
comparing the structure of the polypeptide backbone of non- $\mathrm{CF}$ and $C F$ mucins. TBM isolated from pooled CF lung mucus samples has, however, provided information on the structure of the oligosaccharide chains (6-8). Insufficient information is, as yet, available to allow a comparison of the non-CF and $C F$ oligosaccharide TBM structures. If marked differences, e.g. a shorter size and decreased length of the CF oligosaccharides, are found, then the possibility of partial degradation of CF TBM oligosaccharide chains by bacterial glycosidases may have to be examined.

Acknowledgments. M.C.R. gratefully acknowledges Dr. Ted Beale, Department of Pathology, University of Michigan and Veterans Administration Hospital, Ann Arbor, MI and the members of the Department of Pathology, Children's Hospital National Medical Center, Washington, D.C. for providing tissue specimens.

\section{REFERENCES}

1. DiSant'Agnese PA, Davis P 1976 Research in cystic fibrosis. N Engl J Med 295:481-485

2. Wood RE, Boat TF, Doershuk CF 1976 Cystic fibrosis: state of the art. Am Rev Respir Dis 113:833-878

3. Gibbons AA, Sellwood R 1973 The macromolecular biology of cervical secretions. In: Blandau RJ, Moghissi K (eds) The Biology of the Cervix. University of Chicago Press, Chicago, pp 251-265

4. Litt M, Khan MA, Chakrin LW, Wardell JR Jr, Christian P 1975 Viscoclasticity of fractionated canine tracheal mucus. Biorheology 11:111-116

5. Rose MC, Lynn WS, Kaufman B 1979 Resolution of the major components of human lung mucosal gel and their capabilities for reaggregation and gel formation. Biochemistry 18:4030-4037

6. Roussel P, Lamblin G, Degand P, Walker-Nasir E, Jeanloz RW 1975 Heterogeneity of the carbohydrate chains of sulfated bronchial glycoproteins isolated from a patient suffering from cystic fibrosis. J Biol Chem 250:2114-2122

7. Van Halbeek H, Dorland L, Vliegenthart JFG, Hull WE, Lamblin G, Lhermitte M, Boersma A, Roussel P 1982 Primary-structure determination of fourteen neutral oligosaccharides derived from bronchial-mucus glycoproteins of patients suffering from cystic fibrosis, employing $500 \mathrm{MHz}$ 'H-NMR spectroscopy. Eur J Biochem 127:7-20

8. Lamblin G, Boersma A, Klein A, Roussel P, Van Halbeek H, Vliegenthart JFG 1984 Primary structure determination of five sialylated oligosaccharides derived from bronchial mucus glycoproteins of patients suffering from cystic fibrosis. J Biol Chem 259:9051-9058

9. Rose MC 1988 Epithelial mucous glycoproteins and cystic fibrosis. Horm Metab Res (in press)

10. Boat TF, Kleinerman JI, Carlson DM, Maloney WH, Matthews LW 1974 Human respiratory tract secretions: mucous glycoproteins secreted by cultured nasal polyp epithelium from subjects with allergic rhinitis and with cystic fibrosis. Am Rev Respir Dis 1 10:428-441

11. Barton AD, Weiss SG, Lourenco RV, Dralle WM, Shamsuddin M 1977 Mucus glycoprotein content of chronic bronchitis sputum. Proc Soc Exp Biol Med 156:8-13

12. Sachdev GP, Myers FJ, Horton FO, Fox OF, Wen G, Rogers RM, Carubell R 1980 Isolation, chemical composition and properties of the major mucin component of normal human tracheobronchial secretions. Biochem Med 24:82-94

13. Williams IP, Hall RL, Miller RJ, Richardson PS 1982 Analyses of human tracheobronchial mucus from healthy subjects. Eur J Respir Dis 63:510-515

14. Hoiby N, Schoitz 1982 Pulmonary infections in cystic fibrosis. Acta Pediatr Scand [Suppl] 301:1-132

15. Hastie AT, Hingley ST, Kueppers F, Higgins ML, Tannenbaum CS, Weinbaum G 1983 Protease production by Pseudomonas aeruginosa isolates from patients with cystic fibrosis. Infect Immun 40:506-513

16. Jackson AH, Hill SL, Afford SC, Stockley RA 1984 Sputum sol-phase proteins and elastase activity in patients with cystic fibrosis. Eur J Respir Dis 65:114124

17. Suter S, Schaad UB, Roux L, Nydegger UE, Waldvogel FA 1984 Granulocyte neutral proteases and Pseudomonas elastase as possible causes of airway damage in patients with cystic fibrosis. J Infect Dis 149:523-53

18. Bruce MC, Poncz L, Klinger JD, Stern RC, Tomashefski JF Jr, Dearborn DG 1985 Biochemical and pathologic evidence for proteolytic destruction of lung connective tissue in.cystic fibrosis. Am Rev Respir Dis 132:529-535

19. Spiro RG 197.2 Study of the carbohydrates of glycoproteins. Methods Enzymol 28:3-43
20. Bhatti T. Chambers RE. Clamp JR 1970 The gas chromatographic properties of biologically important $N$-acetylglucosamine derivatives, monosaccharides, disaccharides, trisaccharides, tetrasaccharides and pentasaccharides. Biochim Biophys Acta 222:339-347

21. Aminoff D 1961 Methods for the quantitative estimation of $N$-acetylneuraminic acid and their application to hydrolysates of sialomucoids. Biochem $\mathrm{J}$ 81:384-392

22. Spencer B 1960 Ultramicro determination of inorganic sulfate. Biochem J $75: 435-440$

23. Silvestri LJ, Hurst RE. Simpson L, Settine JM 1982 Analysis of sulfate in complex carbohydrates. Anal Biochem 123:303-309

24. Takagi T, Tsujii K. Shirahama K 1975 Binding isotherms of sodium dodecyl sulfate to protein polypeptides with special reference to SDS-polyacrylamide gel electrophoresis. J Biochem 77:939-947

25. Kabat EA, Mayer MM 1961 Experimental immunochemistry. Charles C Thomas, Springfield, IL, p 127

26. Holden KG, Yim NCF, Griggs LJ, Weisbach JA 1971 Gel electrophoresis of mucous glycoproteins. II. Effect of physical deaggregation and disulfide-bond cleavage. Biochemistry 10:3110-3113

27. Boat TF. Kleinerman JI. Fanaroff AA, Matthews LW 1973 Toxic effect of oxygen on cultured human neonatal respiratory epithelium. Pediatr Res 7:607-615

28. Boat TF, Kleinerman JI 1975 Human respiratory tract secretions: effect of cholinergic and adrenergic agents on in vitro release of protein and mucous glycoprotein. Chest 67:325-345

29. Kornfeld R, Kornfeld S 1981 Structure of glycoproteins and their oligosaccharide units. In: Lennarz WJ (ed) The Biochemistry of Glycoproteins and Proteoglycans; Plenum Press, NY, pp 1-34

30. Lowry OH, Rosebrough NJ, Farr AL. Randall RJ 1951 Protein measuremen with the Folin phenol reagent. J Biol Chem 193:265-275

31. Dubois M, Gilles KA, Hamilton JK. Rebers PA, Smith F 1956 Colorimetric method for determination of sugars and related substances. Anal Chem 28:350-356

32. Kabat EA 1976 Structural Concepts in Immunology and Immunochemistry, 2nd ed. Holt. Rinehart and Winston, NY, pp 191, 196-197

33. Boat TF, Cheng PW, Iyer RN, Carlson DM, Polony I 1976 Human respiratory tract secretions: Mucous glycoproteins of nonpurulent tracheobronchia secretions and sputum of patients with bronchitis and cystic fibrosis. Arch Biochem Biophys 177:95-104

34. Acker DN, 1982 Rheological measurements of human mucosal gels and mucin glycoproteins. M.S. Thesis, Department of Biomedical Engineering, Duke University, Durham, NC

35. Matthews LW, Spector S, Lemm J, Potter J 1963 Studies on pulmonary secretions. Am Rev Respir Dis 88:199-204

36. Cheng PW, Sherman JM, Boat TF, Bruce M 1981 Quantitation of radiolabeled mucous glycoproteins secreted by tracheal explants. Anal Biochem 117:301306

37. Roberts GP 1976 The role of disulfide bonds in maintaining the gel structure of bronchial mucus. Arch Biochem Biophys 173:528-537

38. Feldhoff PA. Bhavanandan VP. Davidson EA 1979 Purification. properties and analysis of human asthmatic bronchial mucin. Biochem 18:2430-2436

39. Rose MC. Kaufman B 1985 Glycosylated and non-glycosylated domains of human tracheobronchial mucus glycoprotein. In: Davidson EA. Williams JC. DiFerrante NM (eds) Glycoconjugates: Proceedings of the VIIIth International Symposium. Praeger Scientific, NY, p $\rho$ 97-98

40. Havez R. Roussel P, Degand P. Randoux A, Biserte G 1968 Biochemical explorations of bronchial hypersecretion. In: Peeters $H$ (ed) Protides Biol Fluids 16. Pergamon Press, NY, pp 343-360

41. Roberts GP 1974 Isolation and characteristics of glycoproteins from sputum Eur J Biochem 50:265-280

42. Creeth JM, Bhaskar KR, Horton JR, Das I, Lopez-Vidriero MT, Reid L 1977 The separation and characterization of bronchial glycoproteins by density gradient methods. Biochem J 167:557-569

43. Woodward H, Horsey B. Bhavanandan VP, Davidson EA 1982 Isolation. purification, and properties of respiratory mucus glycoproteins. Biochem 21:694-701

44. Doring G, Goldstein W, Roll A, Schiotz PO, Hoiby N, Botzenhart K 1985 Role of Pseudomonas aeruginosa exoenzymes in lung infections of patients with cystic fibrosis. Infect Immun 49:557-562

45. Klinger JD, Tandler B, Liedtke CM, Boat TF 1985 Proteinases of Pseudomonas aeruginosa evoke mucin release by tracheal epithelium. J Clin Invest $74: 1669-1678$

46. Carlstedt 1, Sheehan JK 1984 Is the macromolecular architecture of cervical, respiratory and gastric mucins the same? Biochem Soc Trans 12:615-617

47. Rose MC Voter WA, Brown CF, Kaufman B 1984 Structural features of human tracheobronchial mucus glycoprotein. Biochem J 222:371-377

48. Reynolds HY, Newball HH 1974 Analysis of proteins and respiratory cells obtained from human lungs by bronchial lavage. J Lab Clin Med 84:559573 